\title{
IMPLANTAÇÃO E USO DE UM SISTEMA DE MONITORAMENTO AUTOMATIZADO PARA AVALIAÇÃO DA PRODUÇÃO DE POÇOS EM REGIÃO DE OCORRÊNCIA DO SISTEMA AQUÍFERO SERRA GERAL
}

\author{
IMPLEMENTATION AND USE OF AN AUTOMATED MONITORING SYSTEM \\ FOR WELLS PRODUCTION EVALUATION IN OCCURRENCE REGION OF \\ SERRA GERAL AQUIFER SYSTEM

Tuane de Oliveira Dutra ${ }^{1}$; Pedro Antonio Roehe Reginato ${ }^{2}$; Marcos Imério Leão ${ }^{3}$; Gustavo Barbosa Athayde ${ }^{4}$; Rosana Alves Paim ${ }^{5}$

Artigo recebido em: 22/06/2016 e aceito para publicação em: 27/10/2016.

DOI: http://dx.doi.org/10.14295/ras.v30i3.28647

\begin{abstract}
Resumo: O presente estudo foi realizado no município de Carlos Barbosa, localizado na região nordeste do estado do RS, que é abastecido exclusivamente por águas subterrâneas do Sistema Aquífero Serra Geral (SASG). Neste município foi instalado um sistema de monitoramento automatizado, denominado de SIGAS, em 12 dos 15 poços tubulares que captam água do SASG e são utilizados pela CORSAN para o abastecimento público de água no munícipio. O SIGAS monitora volume, vazão e tempo de bombeamento de 15 em 15 minutos e nível de água de 1 em 1 minuto. Foram analisados os dados coletados em 3 poços dos 12 que possuem o sistema. Os dados coletados indicaram que os 3 poços estão trabalhando, na maior parte do período monitorado, acima do tempo de bombeamento projetado, com tempos sem bombeamento operados de forma descontínua. O SIGAS se demostrou um sistema satisfatório para o monitoramento de poços tubulares, inseridos no Sistema Aquífero Serra Geral e utilizados para o abastecimento público, possibilitando a identificação da influência da demanda na operação dos mesmos e o reflexo desta operação nos níveis de água do aquífero no poço. Devido à frequência de coleta de dados e o fácil acesso aos mesmos pelo órgão gestor dos poços, o SIGAS se demostrou ser uma ferramenta de utilidade impar na gestão dos poços.
\end{abstract}

Palavras-chave: Monitoramento quantitativo. Aquíferos fraturados. Águas subterrâneas.

Abstract: This study was fulfilled in the city of Carlos Barbosa, located in northeastern Rio Grande do Sul state, which is supplied exclusively by groundwater from the Serra Geral Aquifer System (SASG). In this municipality it was installed an automated monitoring system, denominated SIGAS in 12 of the 15 wells that capture water from SASG and are used by CORSAN to the public water supply in the municipality. The SIGAS monitors volume, flow rate and pumping time 15 in 15 minutes and level of water in 1 in 1 minute. Were analyzed data collected in 3 wells 12 having the system. The data collected indicated that the 3 wells are working, in most of the monitored period, above the pumping time designed, operated with without pumping time discontinuously. The SIGAS proved to be a satisfactory system for monitoring wells, inserted in the Serra Geral Aquifer System and used for public supply, enabling the identification of the influence demand in the operation thereof, and the reflection of this operation we aquifer water levels well. Due to data collection frequency and easy access thereof by the managing body of the wells, the SIGAS shown to be an odd utility tool in the management of the wells.

Keywords: Quantitative Monitoring. Fractured aquifers. Groundwater.

\section{INTRODUÇÃO}

A demanda pelo recurso hídrico subterrâneo é crescente, na medida em que, somente os recursos hídricos superficiais não atendem de forma integral as necessidades por água, impostas pelo crescimento populacional e econômico. Em algumas regiões do país ás

1-5 Universidade Federal do Rio Grande do Sul (UFRGS), Porto Alegres, RS - E-mails: (tuanehidrica@gmail.com; pedro.reginato@ufrgs.br; imerio@iph.ufrgs.br; gustavo.athayde@ufrgs.br; rosana.a.paim@gmail.com) 
águas subterrâneas resultam na única fonte de recurso hídrico disponível.

O Sistema Aquífero Serra Geral (SASG), no estado do Rio Grande do Sul, ocupa cerca de $50 \%$ da área do estado, sendo que esse sistema é caracterizado pela ocorrência de aquíferos fraturados que estão associados às rochas vulcânicas da Formação Serra Geral (Machado et al., 2005). Essa formação geológica é caracterizada por derrames de rochas vulcânicas básicas, intermediárias e ácidas, que possuem diferentes tipos de estruturas (tectônicas e de resfriamento) e espessuras (ROISEMBERG, et al., 2002). Conforme Reginato e Strieder (2006), o SASG no estado do Rio Grande do Sul, é caracterizado pela presença de aquíferos granulares (localizados no manto de alteração das rochas vulcânicas) e fraturados que estão associados as estruturas tectônicas e de resfriamento das rochas vulcânicas.

O SASG é o aquífero mais explotado do estado do Rio Grande do Sul, no entanto, o mesmo não é monitorado. Os monitoramentos sistemáticos existentes no estado estão associados a poços que captam água de outros aquíferos (Sistema Aquífero Guarani e Quaternário Costeiro), sendo que esses poços fazem parte da Rede Integrada de Monitoramento das Águas Subterrâneas (RIMAS) da CPRM (MOURÃO, 2009).

Conforme Mourão (2009), a intensidade de aproveitamento dos aquíferos aliadas a falta de informação resulta em severas perdas e impactos como, por exemplo: rebaixamento significativo dos níveis d'água, supressão ou redução de vazões de nascentes, diminuição das vazões de poços tubulares, avanço de cunhas salinas e abatimentos de terrenos. Logo a falta de monitoramento deixa extremamente vulnerável as fontes de recursos hídricos subterrâneos, que conforme dados do IBGE (2010), no estado do Rio Grande do Sul, representam a fonte única de abastecimento de $59 \%$ do total de seus municípios.

Esse é o caso do Munícipio de Carlos
Barbosa, que está localizado no nordeste do estado e tem como única fonte de abastecimento os poços tubulares, os quais captam água do SASG. A Companhia Riograndense de Saneamento - CORSAN possui a concessão do abastecimento de água na área urbana do munícipio.

Devido a estas características Carlos Barbosa foi o município escolhido para a implantação de um sistema de monitoramento quantitativo automatizado, denominado de SIGAS, o qual foi implantado em 12 dos 15 poços utilizados atualmente para $o$ abastecimento público de água no município.

Desta forma este trabalho tem como meta principal apresentar o sistema de monitoramento automatizado e avaliar a aplicação desse sistema na análise das condições de explotação dos poços tubulares que captam água do SASG, no município de Carlos Barbosa (RS). Este sistema é pioneiro e permite avaliar diferentes parâmetros como vazão, volume, tempo de bombeamento e níveis de água, que são dados de grande importância para o gerenciamento dos poços e do sistema de abastecimento, bem como para estudo dos aquíferos fraturados.

\section{CARACTERIZAÇÃO GERAL DA ÁREA DE ESTUDO}

A área de estudo está localizada no município de Carlos Barbosa, na região nordeste do estado do Rio Grande do Sul. Carlos Barbosa está situado a 676 metros acima do nível do mar, entre as coordenadas geográficas $29^{\circ} 18^{\prime}$ de Latitude Sul e $51^{\circ} 30^{\prime}$ de Longitude Oeste e está inserido na região do Planalto dos Campos Gerais (Figura 1).

$\mathrm{O}$ município faz limite com os municípios de Farroupilha, Garibaldi; Barão, Boa Vista do Sul, São Vendelino e Alto Feliz. Nesse município está localizado o divisor de duas bacias hidrográficas, Taquari-Antas e Caí, possuindo $56 \%$ de sua área na primeira bacia e o restante deste percentual na segunda bacia. 


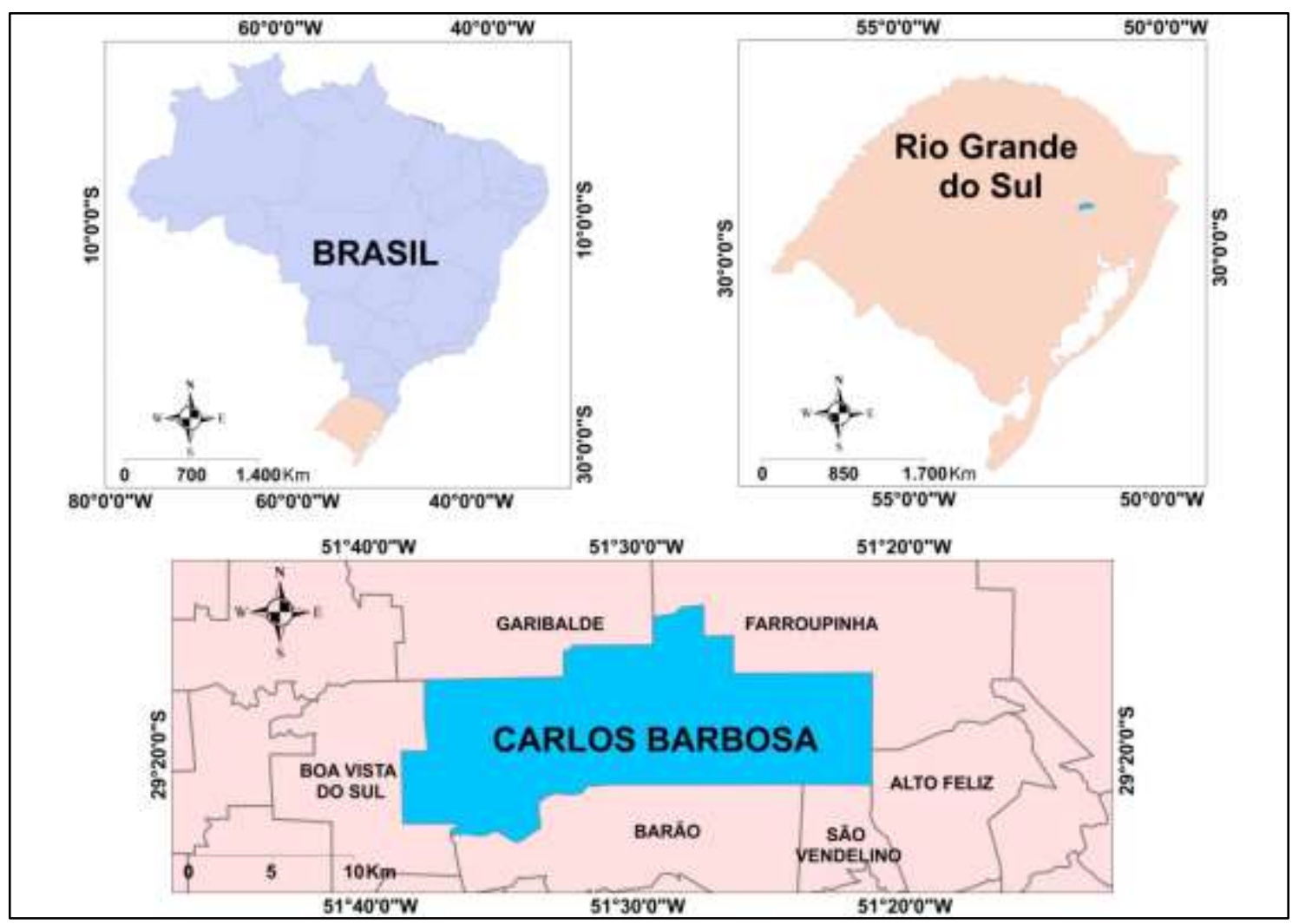

Figura 1 - Localização da área de estudo

Figure 1 - Location of the study area

A geologia da área de estudo é caracterizada pela ocorrência de rochas vulcânicas da Formação Serra Geral. Na área ocorrem rochas ácidas da unidade Palmas/Caxias e básicas da unidade Gramado (CPRM, 2010). As rochas ácidas são representadas por riodacitos e riolitos que estão dispostas em derrames que apresentam espessuras médias de 50 metros e amplas zonas de diaclases horizontais. Já as rochas básicas são representadas por basaltos, estão dispostas em derrames com espessuras médias de 30 metros que apresentam amplas zonas vesiculares a amigdaloides. Para a região de Carlos Barbosa, Bortolin (2014) e Bortolin et al. (2016), identificaram a ocorrência de 7 derrames de rochas vulcânicas, sendo 5 deles ácidos e 2 básicos.

Nessa região os derrames de rochas vulcânicas são cortados por fraturas que possuem mergulhos verticais a sub-verticais que conectam as estruturas horizontais e subhorizontais geradas por diferentes processos (tectônicos, resfriamento e contato entre derrames), promovendo a circulação da água subterrânea pela sequência de rochas vulcânicas (Reginato et al., 2014; Reginato et al., 2015).

De acordo com o mapa hidrogeológico do estado do Rio Grande do Sul (CPRM, 2005), o Sistema Aquífero Serra Geral (SASG) pode ser dividido em três em função de sua produtividade, sendo denominado de SASG I, SASGII e SASG III (Figura 2). Conforme Machado et al. (2005) na área de estudo há ocorrência do SASG II que são representados por aquíferos fraturados associados a riolitos, riodacitos e em menor proporção basaltos. Esses aquíferos apresentam média a baixa produtividade, com capacidades específicas, geralmente inferiores a $0,4 \mathrm{~m}^{3} / \mathrm{h} / \mathrm{m}$. 


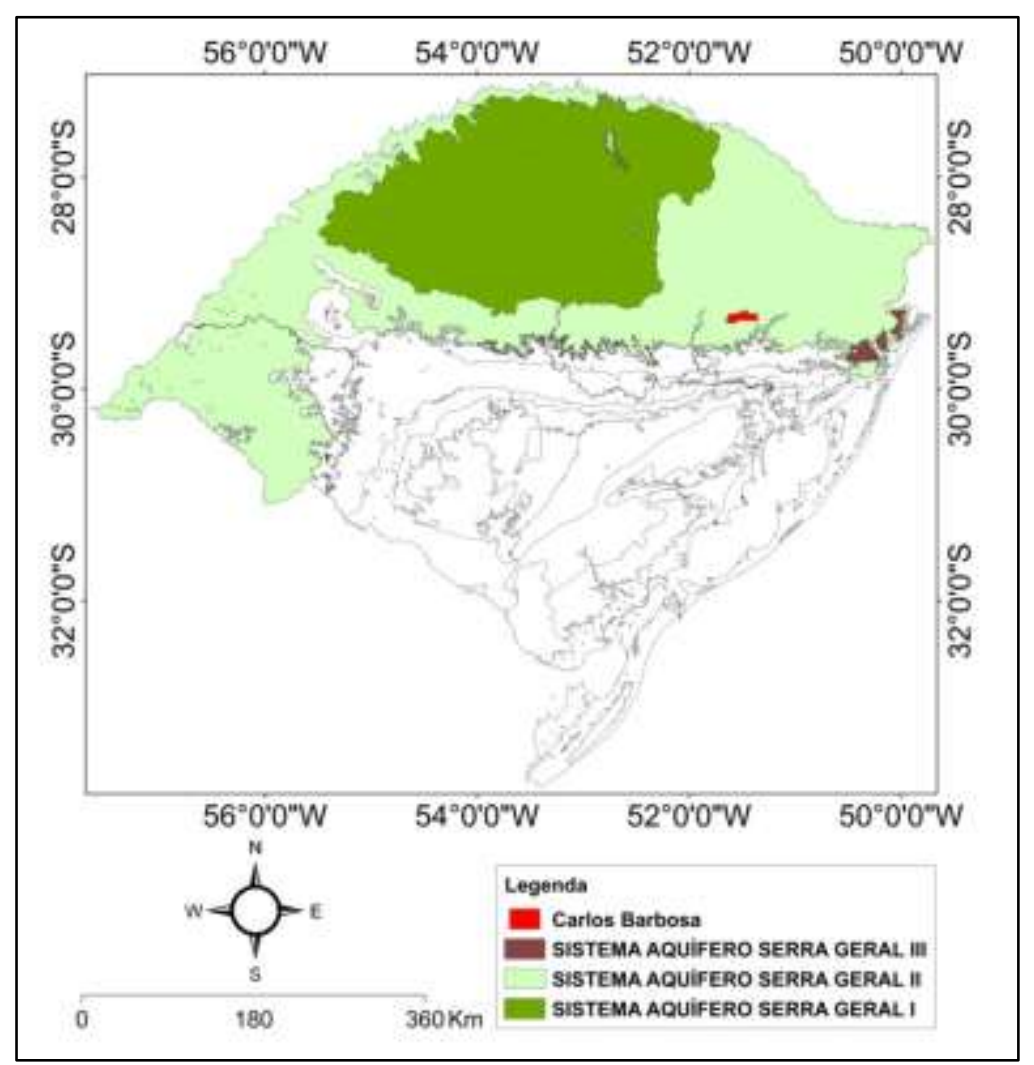

Figura 2 - Contexto hidrogeológico da área de estudo. Fonte: elaborado a partir de Viero e Silva (2010)

Figure 2 - hydrogeological context of the study area. Source: elaborated from Viero and Silva (2010)

O SASG na região de Carlos Barbosa foi estudado por vários autores, cujos trabalhos tiveram enfoques diferentes (locação de poços, caracterização hidrogeológica e estudos hidrogeoquímicos). De acordo com Dias (2013) as principais estruturas que devem ser utilizadas na locação dos poços são as que apresentam orientação noroeste (N0-10W) e N30-50W) e nordeste (N70-80E), pois os poços locados nessas regiões apresentam vazões entre 10 e $50 \mathrm{~m}^{3} / \mathrm{h}$. Já Bortolin et al. (2014), realizaram uma caracterização hidrogeológica da região, que permitiu identificar que os poços tubulares possuem profundidades inferiores a 150 metros $(76 \%)$, 1 a 3 entradas de água $(80 \%)$ que estão localizadas, na sua maioria no intervalo entre 1 e 100 metros de profundidade $(84 \%)$. O nível estático, na maior parte dos poços é inferior a 20 metros $(73 \%)$, as capacidades específicas são inferiores a $1 \mathrm{~m}^{3} / \mathrm{h} / \mathrm{m} \quad(84 \%)$, as transmissividades são menores que $1 \mathrm{~m}^{2} / \mathrm{h}$ $(84 \%)$ e as vazões inferiores a $20 \mathrm{~m}^{3} / \mathrm{h}(80 \%)$. Já Bortolin et al., (2016) identificaram que as águas subterrâneas do SASG na região são, em geral, bicarbonatadas com concentração variável de cálcio, magnésio e sódio e, baixa concentração de sulfatos e cloretos. Além disso, esses autores demonstraram que há uma relação da composição da água subterrânea com a profundidade de ocorrências das fraturas (entradas de água nos poços).

\section{METODOLOGIA}

\subsection{Caracterização do sistema de monitoramento}

O presente trabalho foi realizado a partir de dados coletados pelo Sistema Integrado de Gestão de Águas Subterrâneas (SIGAS), o qual foi desenvolvido para o projeto Hidrofrat (Hidrogeologia de Aquíferos Fraturados), com o objetivo de permitir a coleta, armazenamento e a consulta de dados, em tempo real. O sistema foi implantado em 12 dos 15 poços utilizados pela CORSAN, que é a companhia responsável 
pelo abastecimento público no município de Carlos Barbosa. A estrutura física do SIGAS está instalada em cavaletes de monitoramento (Figura 3C), bem como nas casas de proteção onde estão instalados outros equipamentos como o quadro de comando da bomba do poço (Figura 3 B) e o Data Logger responsável pela armazenamento e envio dos dados coletados pelos sensores e o transdutor de corrente (Figura 3A).

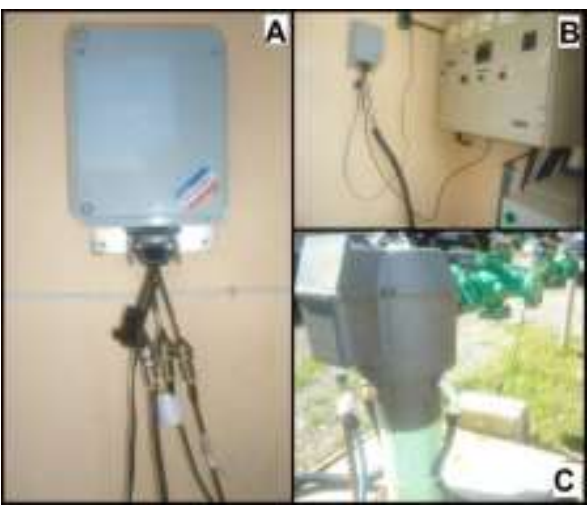

Figura 3 - (A) Data logger, (B) Quadro de comendo da bomba e (C) Cavalete de monitoramento Figure 3 - (A) Data logger, (B) The pump control panel and (C) Easel monitoring

Neste sistema são monitorados três parâmetros: nível de água, volume explotado e corrente da bomba, os quais são monitorados por um conjunto de equipamentos, que é composto de um processador que coleta os sinais dos sensores os quais são descritos a seguir:

- Sensor analógico de pressão com sinais de 4 a $20 \mathrm{~mA}$, responsável pela coleta dos sinais de níveis de água;

- Sensor de pulso (um pulso equivale a 100 litros) instalado no hidrômetro do cavalete, responsável pela coleta de dados do volume explotado;

- Transformador de corrente com saída 4-20 mA, instalado no quadro de comando da bomba. Esse transformador possui um intervalo de $0-50$ A e foi acoplado ao cabo de uma das fases que alimenta a bomba. Assim quando a bomba é ligada é identificada a existência de corrente sendo a mesma medida, armazenada e enviada para o SIGAS.

O sensor utilizado para medir o nível, realiza a medição calculando as variações da coluna de água existente acima de seu ponto de instalação, conhecendo a profundidade de instalação e a profundidade do poço, o logger determina o nível e armazena esse dado. $\mathrm{O}$ fundo de escala dos sensores de nível varia entre os poços devido a maiores ou menores variações das colunas de água a serem monitoradas.

Estes dados são enviados para o SIGAS através do sistema de telefonia celular. Os dados de volume e corrente são enviados a cada 15 minutos e os de níveis de água a cada 1 minuto. A partir dos parâmetros de corrente e volume, o SIGAS é capaz de gerar outros dados como:

- Tempo de bombeamento: através da detecção de corrente da bomba;

- Vazão: como o volume é enviado a cada 15 minutos, a vazão é obtida dividindo o volume por 0,25 (valor referente a um quarto de hora).

O sigas é um sistema voltado para a gestão dos poços utilizados pela CORSAN. Desta forma, o layout do sistema (Figura 4), foi desenvolvido para facilitar o acesso e a interpretação dos dados coletados pelo SIGAS. Logo o sistema possui diferentes módulos como: armazenamento e tabulação de dados, controle on-line do poço, acesso imediato a tabelas e gráficos, armazenamento e controle dos dados cadastrais. 


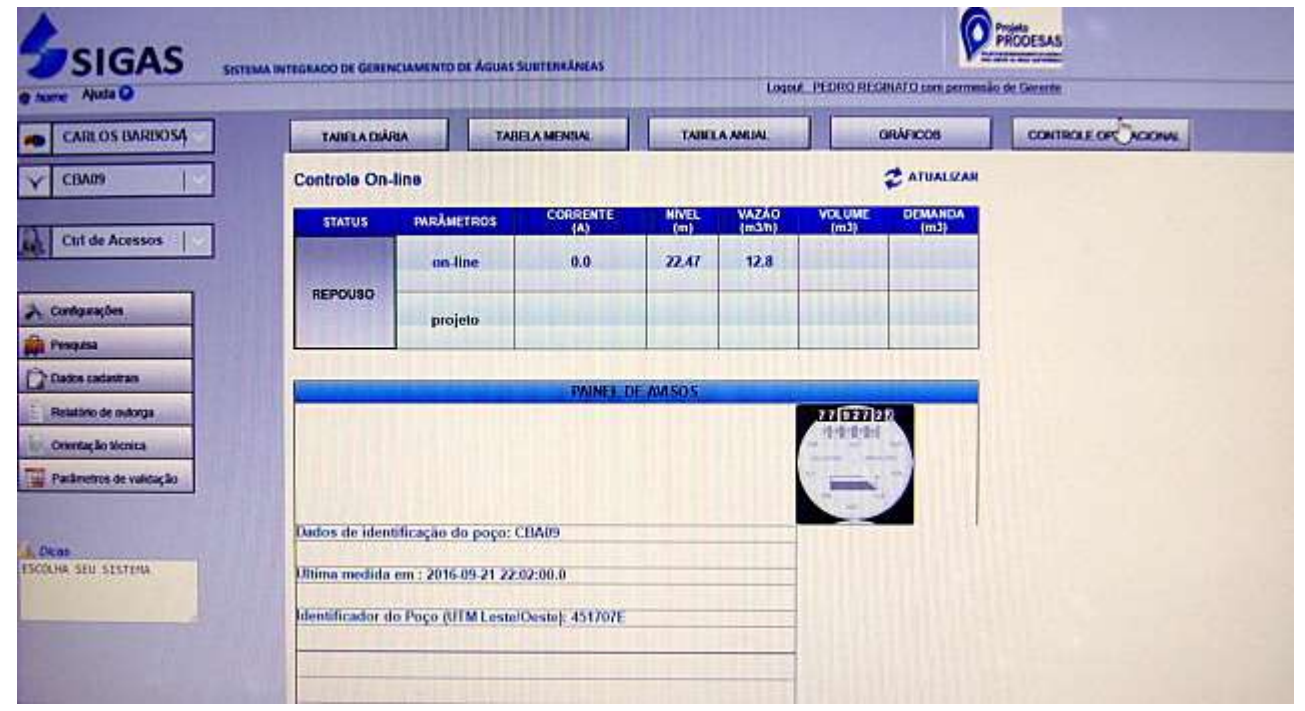

Figura 4 - Layout do Sigas

Figure 4 - Layout of the Sigas

Com o controle on-line é possível acessar os dados operacionais do poço em tempo real, sendo que no painel de avisos são fornecidos dados básicos do poço, assim como a data e horário do último dado que foi medido e enviado para o SIGAS do poço selecionado. Como o SIGAS armazena todos os dados que foram coletados é possível gerar gráficos e tabelas para períodos diários, semanais, mensais ou estipulados dos diferentes parâmetros. Desta forma o SIGAS permite acompanhar de forma rápida $\mathrm{e}$ automática a produção dos poços para diferentes intervalos e avaliar o comportamento individual de cada poço e realizar uma melhor gestão da explotação da água subterrânea.

O sistema proposto neste trabalho tem o intuito de proporcionar o nível de detalhamento necessário para a realização da gestão de poços situados em aquíferos fraturados e utilizados para o abastecimento público. Contudo, esse sistema possui limitações que serão descritas a seguir.

\subsubsection{Limitações do sistema de monitoramento do SIGAS}

O SIGAS possuí algumas limitações em relação à precisão na coleta e envio dos dados, os quais estão associados aos equipamentos utilizados e o sistema de transmissão dos mesmos.

A precisão dos sensores de nível de água é de $1 \%$ do fundo de escala, sendo que, outra fonte de erro na medição do nível é oriundo da profundidade de instalação, sendo que este não é um erro instrumental propriamente dito, mas sim um erro operacional, pois qualquer variação na instalação da mesma também configurará em uma fonte de erro.

Dependendo das condições de tráfego do sistema de telefonia celular o tempo para transmissão dos dados coletados pode levar mais de um minuto. Enquanto está transmitindo os dados o sistema não monitora, portanto isto pode levar, esporadicamente, a perda de dados em um ou dois minutos.

\subsection{Monitoramento realizado pela CORSAN}

Para indicar as vantagens do sistema de monitoramento proposto neste trabalho, além de compreender e analisar as limitações do mesmo, foi feita uma comparação dos valores obtidos pelo sistema com os valores que são monitorados pela CORSAN (monitoramento não automatizado).

Os parâmetros monitorados pela companhia são: volume explotado, vazão, tempo de bombeamento e níveis de água. 
Essas informações são coletadas diariamente, manualmente por um técnico da CORSAN, por meio de visitas aos poços. Os níveis de água são medidos pela CORSAN nos poços de forma aleatória, sem frequência ou periodicidade definida, sendo que essas medições são realizadas por meio da utilização de medidores de nível de água manuais.

O volume explotado é medido por meio de hidrômetro, sendo que nos poços em que há monitoramento, ambos os sistemas (CORSAN e SIGAS) utilizam o mesmo equipamento. $\mathrm{Na}$ ausência do hidrômetro o volume é calculado através da vazão, a qual é estimada pelo método volumétrico (utilizando tonel). A definição do tempo de operação da bomba é realizada por dois sistemas: Timer e a Rádio, já o Horimetro é utilizado para registrar o tempo total de funcionamento da bomba. Como os poços possuem Timer, o qual consiste no sistema de acionamento principal da bomba, trabalham apenas dentro do tempo de bombeamento projetado, logo quando esse tempo é atingido o Timer encerra o bombeamento do poço e inicia novamente após o tempo de descanso previsto. Porém com o aumento da demanda o Timer é desligado para o poço voltar a bombear, conforme informações fornecidas pelo técnico da CORSAN responsável pelo monitoramento.

\subsection{Caracterização dos Poços da CORSAN analisados}

Para esse trabalho foram selecionados 3 dos 12 poços que possuem o sistema para exemplificar e avaliar o sistema de monitoramento bem como o uso do SIGAS. A escolha desses 3 poços foi embasada na quantidade de dados de níveis de água disponíveis que foram obtidos com o sistema de monitoramento.

A caracterização dos poços foi realizada através da analise dos perfis construtivos e geológicos dos poços, dados de ensaios de bombeamento e dados de projeto de bombeamento, disponibilizados pela CORSAN. Com isso, foi possível identificar as principais características dos poços (profundidades e parâmetros hidrodinâmicos) bem como avaliar o projeto de explotação que foi definido para cada poço (nível estático, nível dinâmico, capacidade específica, vazão de explotação projetada e tempo com e sem bombeamento).

\subsection{Avaliação da utilização do SIGAS para monitoramento dos poços tubulares}

A avaliação da utilização do SIGAS para o monitoramento dos poços tubulares foi realizada com base na análise do monitoramento individual executado nos poços CBA 3A, 9 e 12.

Foram avaliados todos os parâmetros monitorados pelo SIGAS, para um intervalo de tempo diário, sendo o período total analisado descrito na tabela 1 . Nota-se que na maioria dos meses em que há dados, os mesmos não constituem um período contínuo, possuindo falhas que foram geradas na coleta ou no envio dos dados, bem como em função da necessidade de calibração, ajustes ou manutenção dos diferentes sensores.

No parâmetro de nível de água foram analisados os valores máximos e mínimos observados diariamente nos poços, os quais representam, respectivamente, os valores mais profundos e superficiais atingidos pelo poço diariamente.

Em relação ao parâmetro vazão, o mesmo foi analisado a partir dos valores médios que foram monitorados diariamente. Já o volume de água e o tempo de bombeamento, foram analisados os valores totais diários.

Foi feita uma comparação entre os dados coletados pelos dois sistemas, para avaliar a confiabilidade do SIGAS no monitoramento quantitativo dos poços, bem como demonstrar os benefícios do sistema proposto frente ao atual sistema de monitoramento realizado pela CORSAN.

A aferição dos dados em campo foi realizada apenas para os dados de níveis, sendo utilizado um sensor de nível manual para a realização da mesma. Optou-se por 
aferir somente o parâmetro nível de água, pois o mesmo pode apresentar erros que podem estar associados a outros fatores, como os gerados pela instalação do sensor. Cabe salientar que para o período envolvido nesse trabalho não foi realizado monitoramento de níveis de água pela CORSAN.

Tabela 1 - Período de dias monitorados para análise dos parâmetros de nível de água, vazão, volume e tempo de bombeamento.

Table 1 - Day period monitored for analysis of the parameters water level, flow rate, volume and pumping time

\begin{tabular}{|c|c|c|c|c|}
\hline \multirow[b]{2}{*}{ Mês } & \multirow[b]{2}{*}{ Parâmetro } & \multicolumn{3}{|c|}{ Poços } \\
\hline & & CBA 3A & CBA 9 & CBA 12 \\
\hline \multirow{4}{*}{$\stackrel{n}{a}$} & Nível (m) & & & \\
\hline & Vazão $\left(\mathrm{m}^{3} / \mathrm{h}\right)$ & & & \\
\hline & Volume $\left(\mathrm{m}^{3}\right)$ & 4 a 30 & ….... & ......... \\
\hline & $\begin{array}{c}\text { Tempo de bombeamento } \\
\text { (h) }\end{array}$ & & & \\
\hline \multirow{4}{*}{ 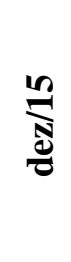 } & Nível (m) & & & \\
\hline & Vazão $\left(\mathrm{m}^{3} / \mathrm{h}\right)$ & & & \\
\hline & Volume $\left(\mathrm{m}^{3}\right)$ & ......... & 27 a 31 & ......... \\
\hline & $\begin{array}{c}\text { Tempo de bombeamento } \\
\text { (h) }\end{array}$ & & & \\
\hline \multirow{5}{*}{$\stackrel{\ominus}{ٍ ٍ \Xi}$} & & 13 a 24 & & \multirow{5}{*}{1 a 26} \\
\hline & Nível (m) & 26 a 31 & & \\
\hline & Vazão $\left(\mathrm{m}^{3} / \mathrm{h}\right)$ & & 1 & \\
\hline & Volume $\left(\mathrm{m}^{3}\right)$ & 6 a 24 & 3 a 27 & \\
\hline & Tempo de bombeamento & 27 a 31 & & \\
\hline \multirow{5}{*}{ 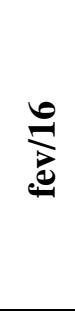 } & & 5 e $6 / 8$ & & \multirow{5}{*}{3 a 29} \\
\hline & Nível (m) & 10 a $15 / 17$ & 15 & \\
\hline & Vazão $\left(\mathrm{m}^{3} / \mathrm{h}\right)$ & & $2 \mathrm{a} 1 \mathrm{~J}$ & \\
\hline & Volume $\left(\mathrm{m}^{3}\right)$ & 5 a 29 & & \\
\hline & $\begin{array}{c}\text { Tempo de bombeamento } \\
\text { (h) }\end{array}$ & & 2 a 29 & \\
\hline
\end{tabular}

\section{RESULTADOS}

\subsection{Caracterização dos poços analisados}

A distribuição espacial dos poços analisados, dos demais poços que possuem o SIGAS instalado, dos poços da CORSAN e dos demais poços cadastrados no município de Carlos Babosa, podem ser visualizados na figura 5, sendo que, os poços analisados estão situados no perímetro urbano do munícipio.

O Perfis construtivo dos 3 poços analisados podem ser visualizados na figura 6. Os poços CBA $3 \mathrm{~A}$ e 12 possuem uma fina camada de solo, sendo que, nos três poços foram identificados uma camada de rocha alterada, a qual foi mais profunda na poço CBA 9, seguida por rochas vulcânicas ácidas e básicas.

Os 3 poços analisados possuem características construtivas e hidrogeológicas relativamente variadas, conforme apresentado na tabela 2. 
DUTRA, T.O.; REGINATO, P.A.R.; LEÃO, M.I.; ATHAYDE, G.B.; PAIM, R.A.

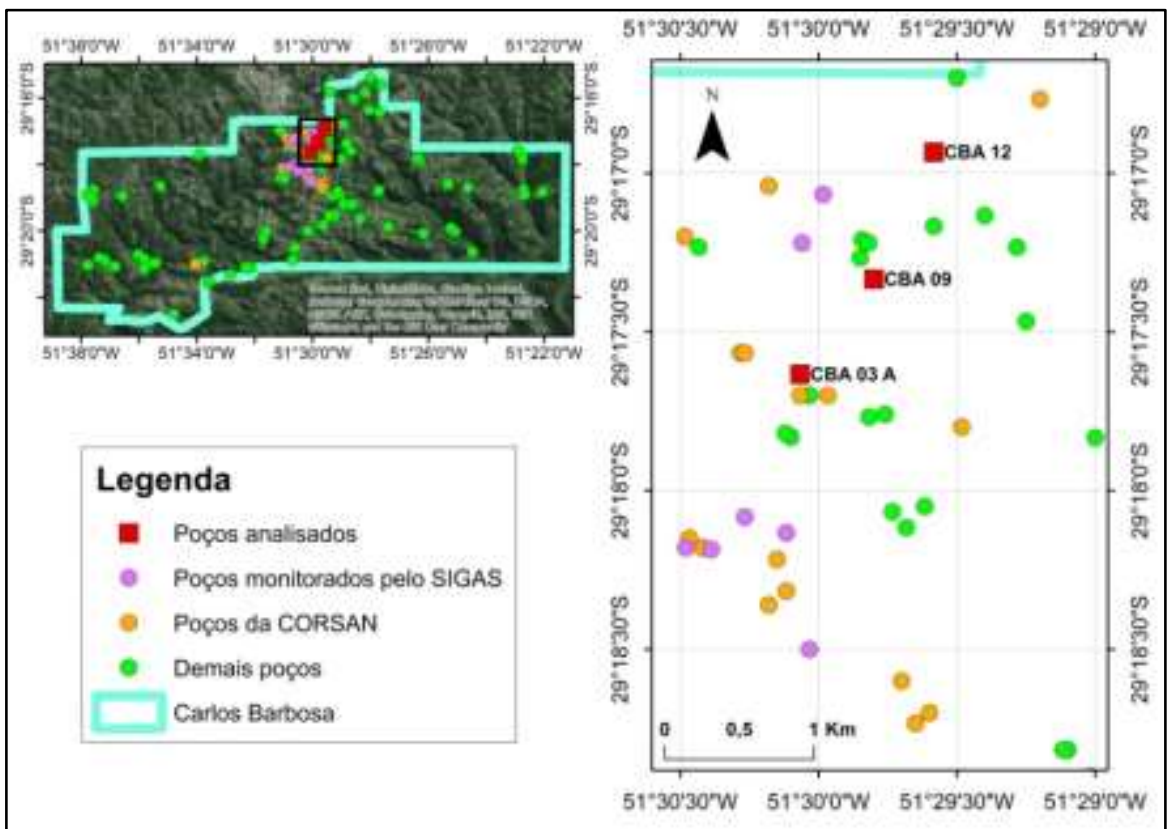

Figura 5 - Localização dos poços

Figure 5 - Location of the wells 


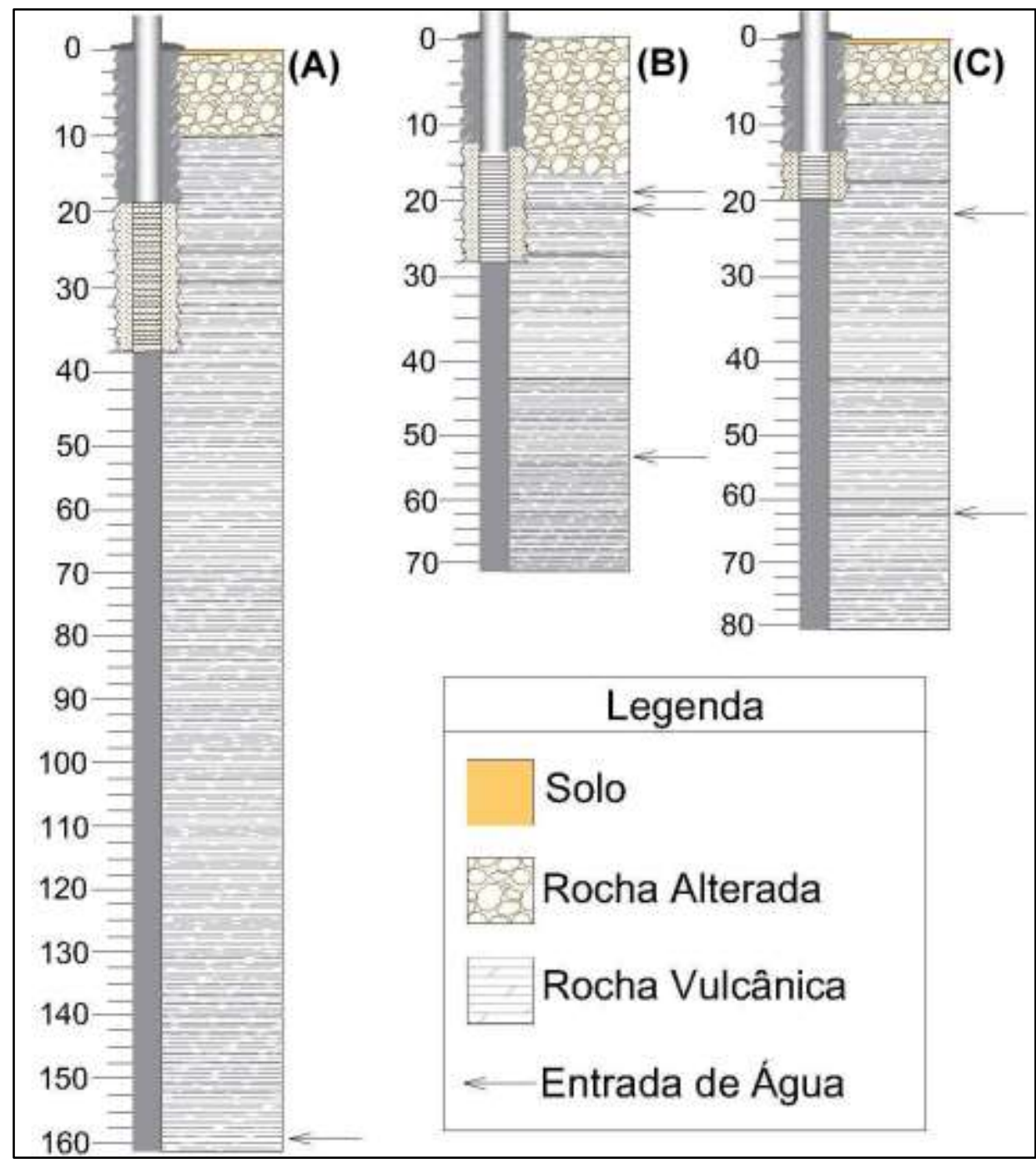

Figura 6 - Perfis construtivos dos poços analisados. (A) Poço CBA 3A. (B)Poço CBA 9. (C)Poço CBA 12 Figure 6-Constructive profiles of analyzed wells. (A) Well CBA 3A. (B) Well CBA 9. (C)Well CBA 12

Conforme a tabela 2, os poços possuem 3 entradas de água, sendo que nos poços CBA $3 \mathrm{~A}$ e 12 a entrada de água mais superficial está selada pelo revestimento. Os níveis estáticos e dinâmicos são diferentes entre os três poços, sendo que ambos os níveis são mais profundos no poço CBA 3A e mais superficiais no poço CBA 12. A capacidade específica dos três poços são baixas, sendo inferiores a $1,6 \mathrm{~m}^{3} / \mathrm{h} / \mathrm{m}$. Considerando que em geral poços que captam água de aquíferos fraturados apresentam baixa produtividade, os três poços possuem vazões satisfatórias. Cada poço possuí um tempo de bombeamento diferente, o qual varia de 12 a 18 horas. 
Tabela 2 - Dados hidrodinâmicos dos poços analisados

Table 2 - Hydrodynamic data of the wells analyzed

\begin{tabular}{ccccccccc}
\hline POÇOS & $\begin{array}{c}\text { PROF. } \\
(\mathbf{m})\end{array}$ & PROF. EA (m) & $\begin{array}{c}\text { PROF. } \\
\mathbf{R E V} \\
(\mathbf{m})\end{array}$ & $\begin{array}{c}\mathbf{N D} \\
(\mathbf{m})\end{array}$ & $\begin{array}{c}\mathbf{N E} \\
(\mathbf{m})\end{array}$ & $\begin{array}{c}\mathbf{Q} \\
\left(\mathbf{m}^{3} / \mathbf{h}\right)\end{array}$ & $\begin{array}{c}\mathbf{q} \\
\left(\mathbf{m}^{3} / \mathbf{h} . \mathbf{m}\right)\end{array}$ & $\begin{array}{c}\text { TB } \\
(\mathbf{h})\end{array}$ \\
\hline $3 \mathrm{~A}$ & 163,65 & $21 ; 26 ; 159$ & 32 & 110 & 22,2 & 45 & 0,513 & 16 \\
9 & 71,5 & $19 ; 23,5 ; 53,5$ & 15,3 & 35 & 15,2 & 30 & 1,513 & 18 \\
12 & 86 & $5 ; 21 ; 61$ & 13 & 24 & 10,3 & 20 & 1,46 & 12 \\
\hline
\end{tabular}

PROF: Profundidade/ EA: Entrada de água/ REV: Revestimento/ ND: Nível dinâmico/ NE: Nível estático/ Q: Vazão/ q: Capacidade específica/ TB: Tempo de bombeamento

\subsection{Avaliação do monitoramento individual do SIGAS em poços}

Foram observados os dados coletados nos poços CBA 3A, 9 e 12 para avaliação do monitoramento individual realizado pelo SIGAS.

\subsubsection{Tempo de bombeamento}

Como o SIGAS recebe dados de corrente de 15 em 15 minutos, é possível detalhar o tempo de bombeamento e sem bombeamento operados nos poços e não somente o tempo total diário, como é registrado atualmente pelo monitoramento realizado pela CORSAN. Desta forma, com os dados do SIGAS é possível analisar a influência da demanda na operação dos poços e verificar se o tempo de bombeamento projetado está sendo respeitado.

Nos três poços utilizados para exemplificar o monitoramento realizado pelo
SIGAS, o tempo de bombeamento operado foi superior ao projetado em $89,47 \%$ do período monitorado no poço CBA $3 \mathrm{~A}, 72,37 \%$ no poço CBA 9 e em $85 \%$ no poço CBA 12 , indicando que o Timer foi desligado em boa parte do período monitorado, nos três poços.

Nas figuras 7, 8 e 9 é possível visualizar os intervalos de tempo com bombeamento e sem bombeamento registrados pelo SIGAS nos três poços, sendo possível observar que além do período sem bombeamento definido em projetado não ser atingido, o mesmo, em quase a totalidade do período analisado, não ocorre de forma contínua. Contudo, foi possível identificar um "padrão" na operação dos poços CBA 9 (Figura 8) e CBA 12 (Figura 9), que por vezes é influênciado pela demanda, ocasionando, desta forma, variações. Já no poço CBA 3A (Figura 7), foi identificada uma maior influência da demanda, sendo que o poço foi operado comumente de forma ininterruptamente, sem descanso.

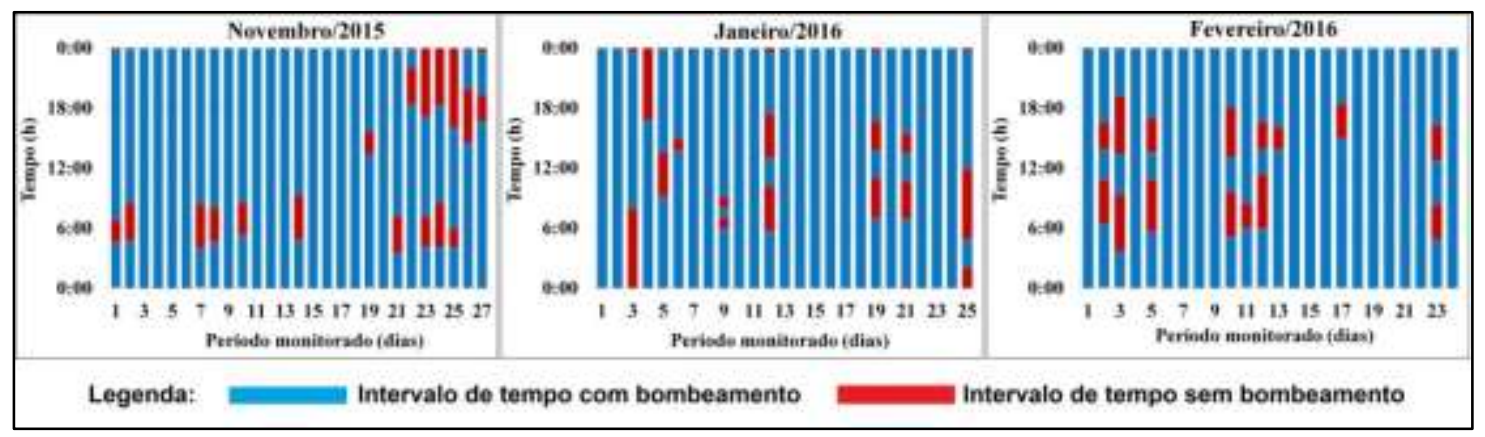

Figura 7 - Intervalos de tempo com e sem bombeamento no poço CBA 3A

Figure 7 - Time intervals with and without pumping into the well CBA 3A 


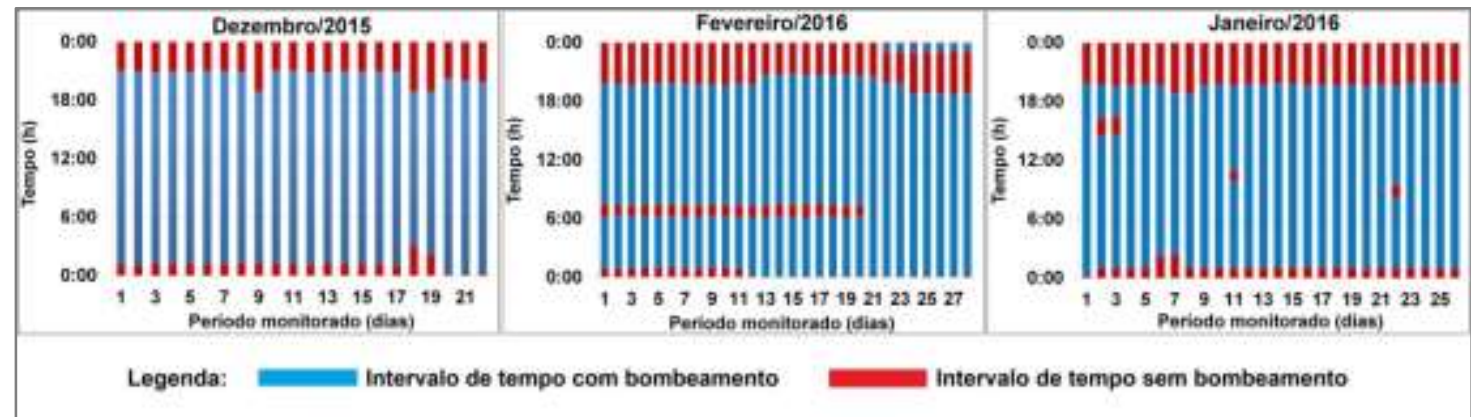

Figura 8 - Intervalos de tempo com e sem bombeamento no poço CBA 9

Figure 8 - Time intervals with and without pumping into the well CBA 9

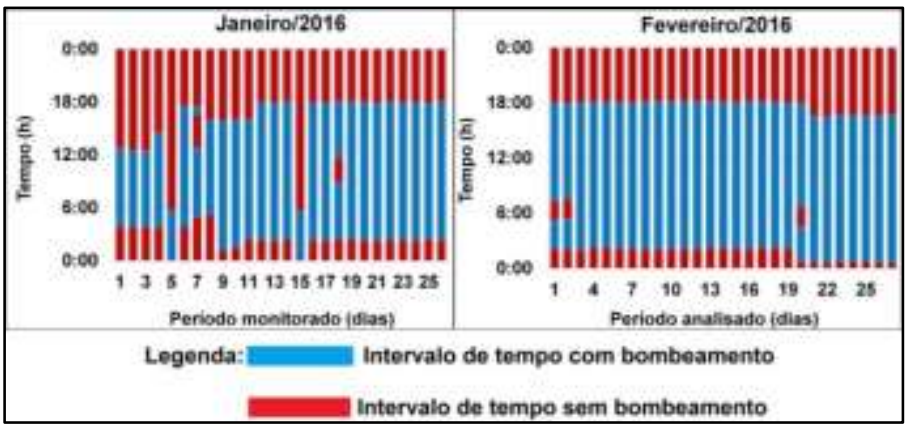

Figura 9 - Intervalos de tempo com e sem bombeamento no poço CBA 12

Figure 9 - Time intervals with and without pumping into the well CBA 12

O monitoramento realizado pelo SIGAS permite conhecer de forma mais detalhada as demandas existente em cada poço e desta forma planejar a melhor forma de atendê-las, respeitando os limites de tempo de bombeamento definido para os poços. $\mathrm{O}$ monitoramento do tempo de bombeamento realizado pela CORSAN, só permite analisar o tempo de bombeamento diário total, no entanto, todos os poços analisados nesse trabalho, assim como os demais poços utilizados pela companhia para o abastecimento de água na cidade, possuem dois sistemas de acionamento da bomba e por esse motivo a operação do poço pode ser influênciada pela demanda dos reservatórios, conforme foi indicado pelo monitoramento realizado pelo SIGAS.

Além disso, o fato da coleta dos dados serem realizadas manualmente por um técnico da companhia inviabiliza a coleta dos dados de tempo de bombeamento no mesmo horário, considerando que há apenas um funcionário para a realização desta atividade. Essa limitação pode viabilizar registros de valores inferiores e/ou superiores aos reais, isso vai depender das variações nos horários de coleta. Esta constatação pode ser observada em valores na tabela 3 e graficamente nas figuras 10,11 e 12 , as quais apresentam os valores coletados por ambos os monitoramentos, CORSAN e SIGAS, para o período monitorado nos três poços. 


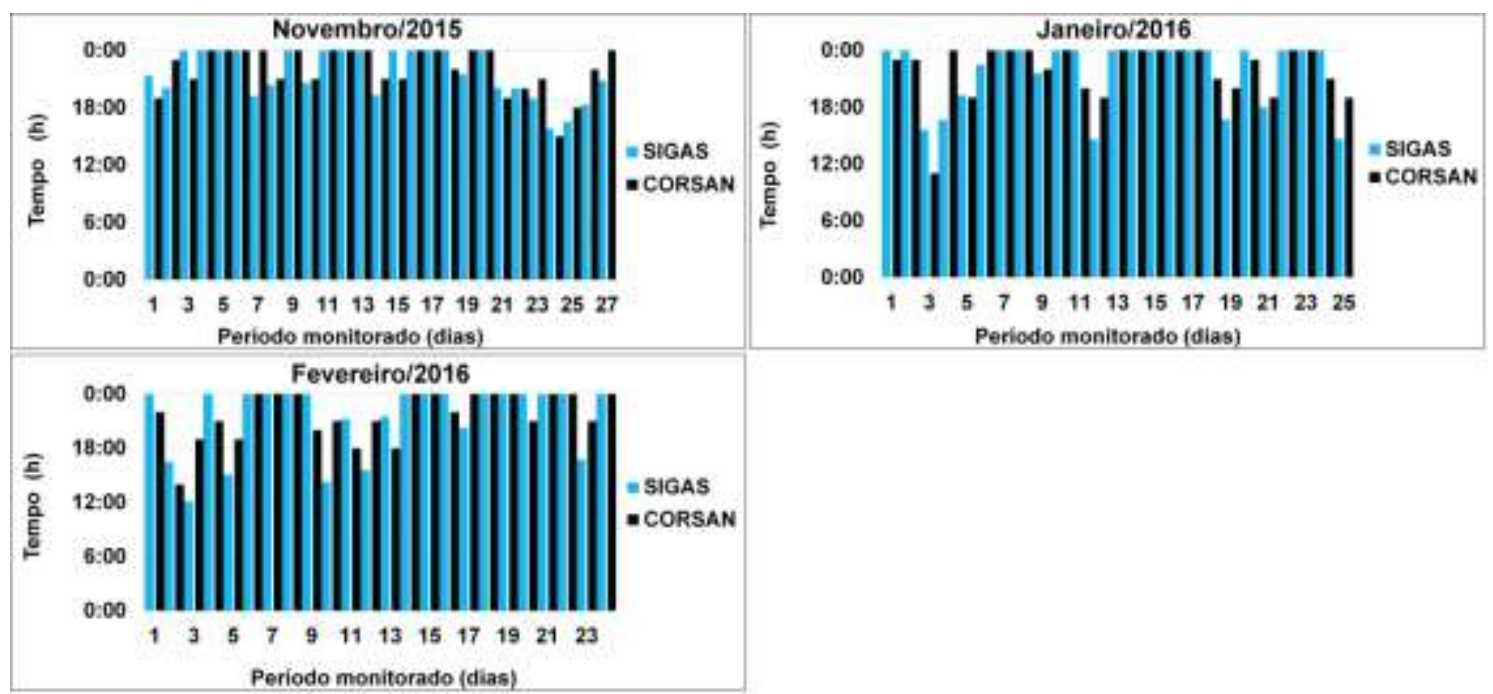

Figura 10 - Tempo de bombeamento no poço CBA 3A monitorados pelo SIGAS e CORSAN

Figure 10 - Pumping time in well CBA 3A monitored by SIGAS and CORSAN

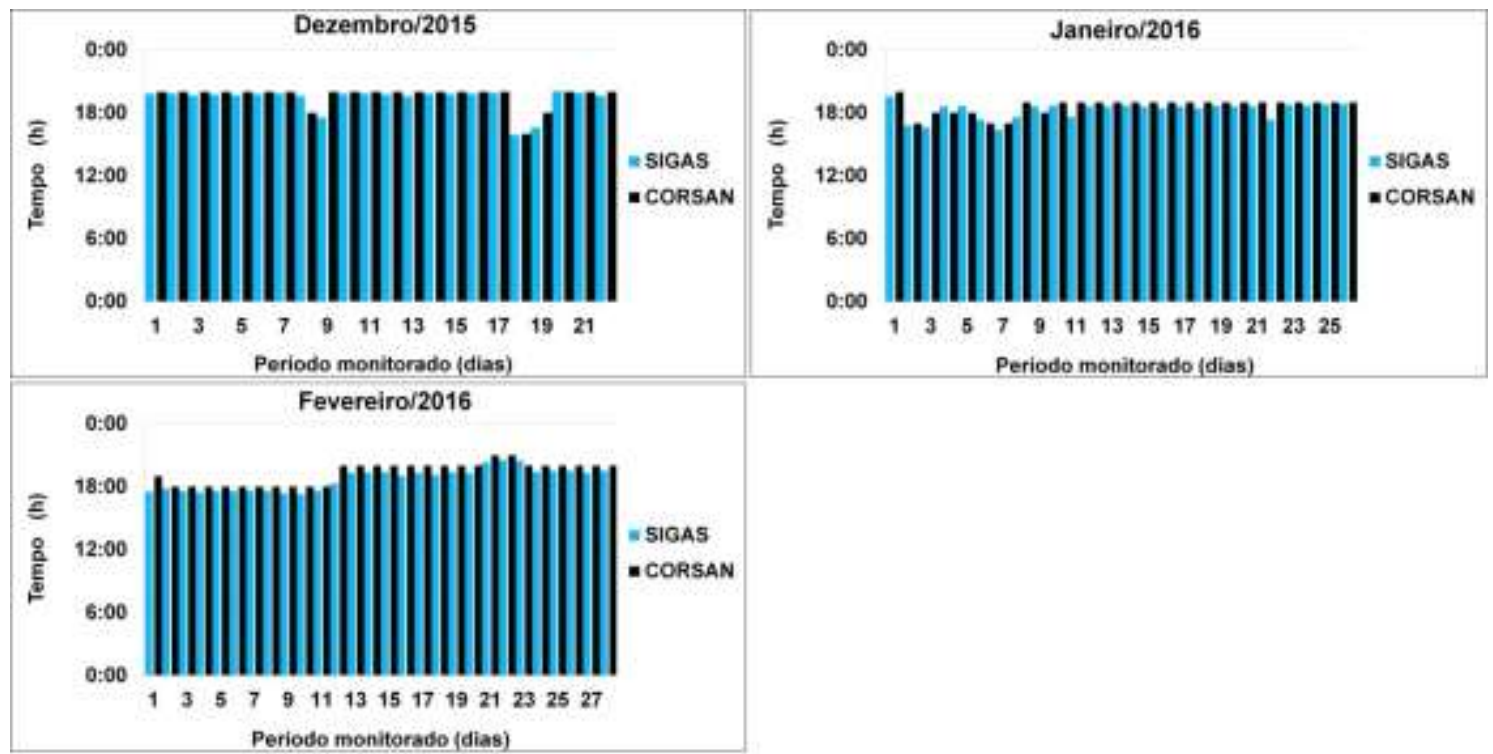

Figura 11 - Tempo de bombeamento no poço CBA 9 monitorados pelo SIGAS e CORSAN

Figure 11 - Pumping time in well CBA 9 monitored by SIGAS and CORSAN

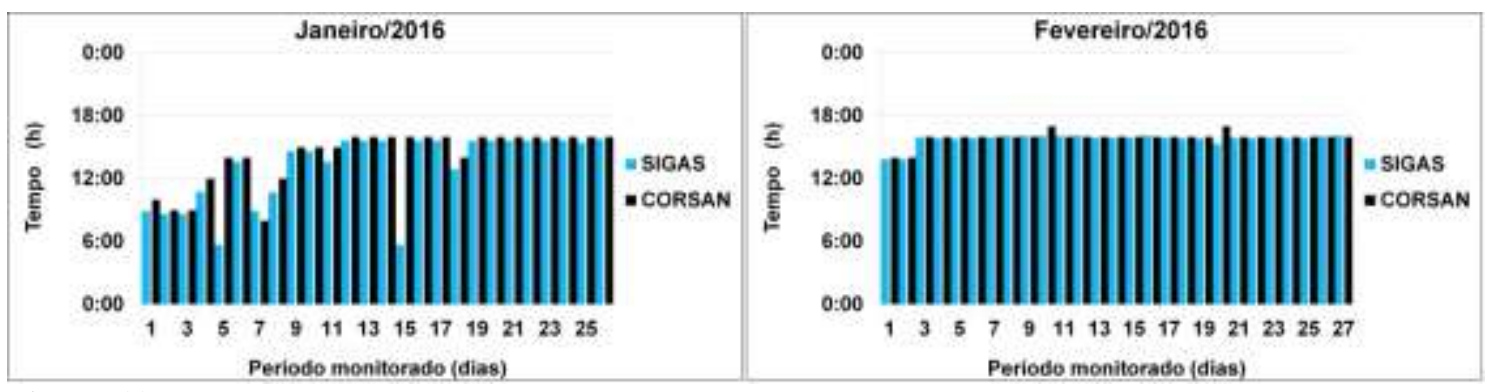

Figura 12 - Tempo de bombeamento no poço CBA 12 monitorados pelo SIGAS e CORSAN

Figure 12 - Pumping time in well CBA 12 monitored by SIGAS and CORSAN 
Nota-se, a partir da tabela 3 , que a diferença média entre os valores coletados por ambos os monitoramentos é significativamente distinta nos três poços, justamente devido à variação no horário de coleta dos dados pelo técnico responsável. Como é possível observar na tabela 3 e nas figuras 10 e 12, nos poços CBA $3 \mathrm{~A}$ e 12 , por vezes, o mesmo valor é coletado por ambos os sistemas. No caso dos poços CBA 3 A, os valores iguais coletados ocorrem nos dias em que o tempo de bombeamento é de 24:00 h e nos poços CBA 12, o qual não trabalha 24:00h, esses dados coincidem nos dias em que o tempo de bombeamento é mais elevado. Em ambos os poços CBA 9 e 12, as diferenças ocorridas foram, em média, inferiores a 1:00h, sendo na maioria, referentes a dados da CORSAN superiores ao do SIGAS. Já no poço CBA $3 \mathrm{~A}$, em média as diferenças foram de quase 3:00h, contudo, por ter sido operado na maior parte do tempo por 24:00 h, obteve um percentual mais elevado de valores coincidentes entre os dois monitoramentos.

Tabela 3 - Análise estatística das diferenças observadas entre os dados de TB coletados pela CORSAN e o SIGAS Table 3 - Statistical analysis of the differences observed between the pumping time of data collected by CORSAN and SIGAS

\begin{tabular}{cccccc}
\hline POÇOS & $\begin{array}{c}\text { CORSAN>SI } \\
\text { GAS }(\%)\end{array}$ & $\begin{array}{c}\text { CORSAN<SI } \\
\text { GAS }(\boldsymbol{\%})\end{array}$ & $\begin{array}{c}\text { CORSAN= } \\
\text { SIGAS }\end{array}$ & $\mathbf{x}(\mathbf{h})$ & $\boldsymbol{\sigma}(\mathbf{h})$ \\
\hline CBA 3 A & 30,26 & 27,63 & 42,11 & $02: 56$ & $1: 41$ \\
CBA 9 & 90,79 & 9,21 & $\ldots$. & $00: 32$ & $00: 26$ \\
CBA 12 & 72 & $\ldots$. & 28 & $00: 46$ & $1: 46$ \\
\hline
\end{tabular}

\subsubsection{Vazão e volume}

O monitoramento dos parâmetros de vazão e o volume, realizados pelo SIGAS nos três poços, podem ser visualizados na figura 13 , onde observa-se que a vazão, em todos os poços, está significativamente abaixo dos valores definidos em projeto e com comportamento pouco variável.

Em relação ao volume, os três poços tiveram comportamentos distintos. No poço CBA 3A (Figura 13B), o volume explotado ultrapassou o projetado, em $50 \%$ do período monitorado, devido aos elevados valores de tempos de bombeamento operados. Já nos poços CBA 9 e 12, os valores de volume monitorados se mantiveram abaixo do definido em projeto, na totalidade do período monitorado, conforme pode ser visualizado na figura 13D e 13F. Contudo, no poço CBA 9 o comportamento dos valores de volume explotado foram menos variáveis que nos poços CBA 12 e $3 \mathrm{~A}$, sendo que a variação dos valores registrados está relacionada, principalmente, a variação nos valores de tempo de bombeamento.

$\mathrm{O}$ diferencial do monitoramento realizado pelo SIGAS é o nível de detalhamento, pois as vazões médias diárias são calculadas com valores de volume coletados de 15 em 15 minutos, possibilitando uma melhor aproximação do real valor operado em campo, tendo maior controle da quantidade de água demandada para o abastecimento público do município. 


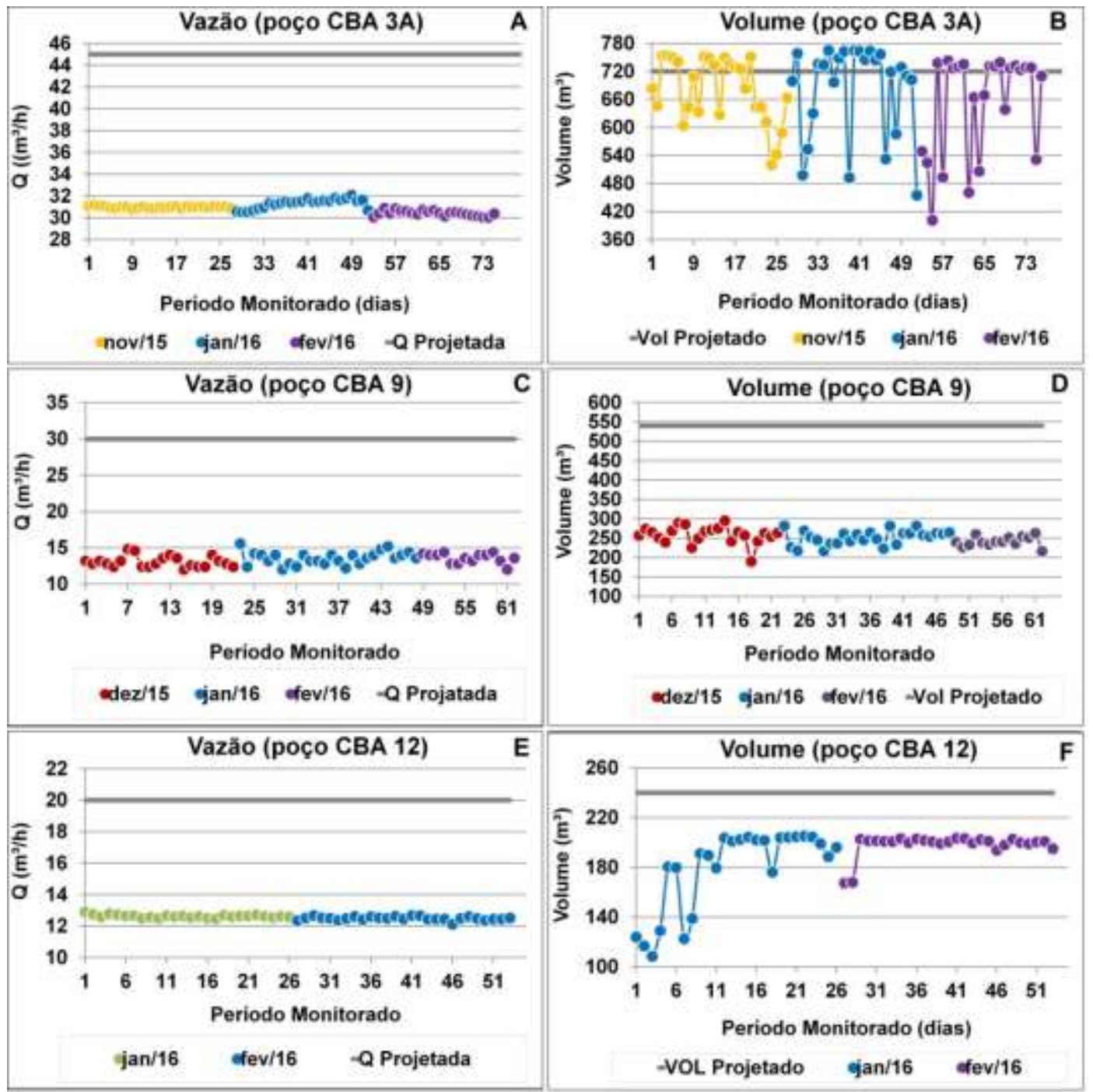

Figura 13 - (A) Dados de vazão monitorados pelo SIGAS no poço CBA 3A. (B) Dados de volume monitorados pelo SIGAS no poço CBA 3A. (C) Dados de vazão monitorados pelo SIGAS no poço CBA 9. (D) Dados de volume monitorados pelo SIGAS no poço CBA 9. (E) Dados de vazão monitorados pelo SIGAS no poço CBA 12. (F) Dados de volume monitorados pelo SIGAS no poço CBA 12

Figure 13 - (A) Flow rate data monitored by SIGAS in the well CBA 3A. (B) Volume data monitored by SIGAS in the well CBA 3A. (C) Flow rate data monitored by SIGAS in the well CBA 9. (D) Volume data monitored by SIGAS in the well CBA 9. (E) Flow rate data monitored by SIGAS in the well CBA 12. (F) Volume data monitored by SIGAS in the well CBA 12

Conforme já exposto, o monitoramento realizado pela CORSAN possibilita o registro de valores superiores e/ou inferiores ao operado em campo, devido à variabilidade no horário de coleta pelo técnico. Na tabela 4 são apresentadas as diferenças dos dados coletados por ambos os monitoramentos, para o parâmetro de volume, sendo possível observar que, com exceção do poço CBA 12 , houve uma maior variação dos valores, fato evidenciado pelos valores de desvio padrão. Nos três poços, em uma porcentagem significativa do período monitorado, os dados monitorados pela CORSAN foram superiores aos coletados pelo SIGAS. Em média, as diferenças maiores foram observadas no poço CBA 3A, o qual possui os valores mais elevados de volumes explotados. 
Tabela 4 - Análise estatística das diferenças observadas entre os dados de volume coletados pela CORSAN e o SIGAS

Table 4 - Statistical analysis of the differences observed between the volume of data collected by CORSAN and SIGAS

\begin{tabular}{ccccc}
\hline POÇOS & CORSAN>SIGAS $(\boldsymbol{\%})$ & $\begin{array}{c}\text { CORSAN }<\text { SIGAS } \\
(\boldsymbol{\%})\end{array}$ & $\begin{array}{c}\mathbf{x} \\
\left(\mathbf{m}^{\mathbf{3}}\right)\end{array}$ & $\boldsymbol{\sigma}\left(\mathbf{m}^{\mathbf{3}}\right)$ \\
\hline CBA 3 A & 77,63 & 22,37 & 78,26 & 53,25 \\
CBA 9 & 98,39 & 1,61 & 24,15 & 14,09 \\
CBA 12 & 96 & 4 & 16,03 & 5,75 \\
\hline
\end{tabular}

Em quase a totalidade do período monitorado, os dados de vazão coletados pela CORSAN foram superiores aos coletados pelo SIGAS, sendo que no poço $3 \mathrm{~A}$ os valores da CORSAN foram mais elevados que os do SIGAS em todo o período monitorado (Tabela 5). Os valores médios de diferenças observados entre os dados de vazão coletados foram poucos variáveis, conforme os dados de desvio padrão. A diferença entre os dois monitoramentos foi maior no poço CBA $3 \mathrm{~A}$, o que é coerente com as diferenças observadas nos parâmetros de tempo de bombeamento e volume, que também foram mais elevados neste poço.

Tabela 5 - Análise estatística das diferenças observadas entre os dados de vazão coletados pela CORSAN e o SIGAS

Table 5 - Statistical analysis of the differences observed between the flow rate of data collected by CORSAN and SIGAS

$$
\text { POÇOS CORSAN }>\text { SIGAS }(\%) \quad \text { CORSAN }<\text { SIGAS }(\%) \underset{\left(\mathbf{m}^{3} / \mathbf{h}\right)}{\mathbf{x}} \underset{\left(\mathbf{m}^{3} / \mathbf{h}\right)}{\boldsymbol{\sigma}}
$$

\begin{tabular}{ccccc}
\hline CBA 3A & 100 & $\ldots$ & 2,33 & 0,46 \\
CBA 9 & 97 & 3 & 1,18 & 0,51 \\
CBA 12 & 98,11 & 1,89 & 0,94 & 0,14 \\
\hline
\end{tabular}

$\mathrm{Na}$ figura 14, é possível visualizar graficamente as diferenças discutidas anteriormente para ambos os parâmetros, volume e vazão. De forma geral os dados de vazão e volume coletados pela CORSAN e o SIGAS possuem o mesmo comportamento de elevação e redução dos valores observados. Para os poços e período analisado, fica clara a existência de uma tendência de superestimativa dos valores desses parâmetros que são monitorados pela CORSAN. 


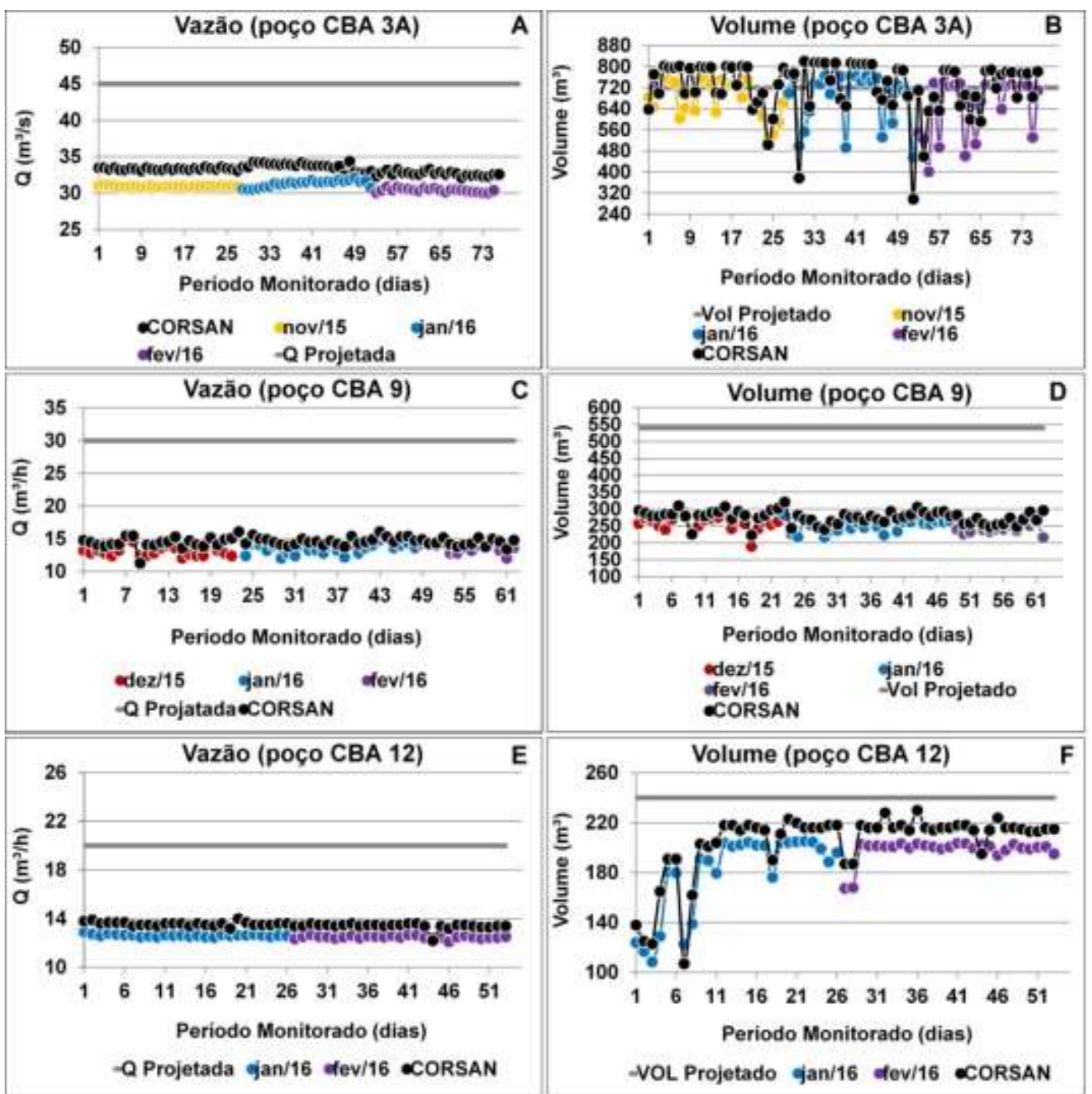

Figura 14 - Comparação dos dados coletados pelo SIGAS e pela CORSAN. (A) Dados de vazão monitorados no poço CBA 3A. (B) Dados de volume monitorados no poço CBA 3A. (C) Dados de vazão monitorados no poço CBA 9. (D) Dados de volume monitorados no poço CBA 9. (E) Dados de vazão monitorados no poço CBA 12. (F) Dados de volume monitorados no poço CBA 2

Figure 14 - Comparison of the data collected by SIGAS and CORSAN. (A) Flow rate data monitored in the well CBA 3A. (B) Volume data monitored in the well CBA 3A. (C) Flow rate data monitored in the well CBA 9. (D) Volume data monitored in the well CBA 9. (E) Flow rate data monitored in the well CBA 12. (F) Volume data monitored in the well CBA 12

\subsubsection{Nível de água}

O SIGAS permite, através do monitoramento detalhado de 1 em 1 minuto do nível de água, saber o reflexo do regime de bombeamento nos poços, como pode ser visualizado nos gráficos da figura 15 , onde é apresentado os valores de níveis de água mais profundos e mais superficiais ocorridos diariamente para o período monitorado nos três poços.

Os poços analisados estão com vazões operadas abaixo do projetado e bombeando, na maior parte do período monitorado, acima do tempo definido em projeto. Contudo, o reflexo da operação no nível de água em cada poço é distinto. No poço CBA 9, a variação do nível ocorreu dentro do intervalo de nível previsto em projeto, contudo, foi possível identificar a dificuldade do retorno do nível de água ao NE de projeto, sendo que tal dificuldade pode estar associada ao tempo de descanso, inferior ao projetado e descontínuo. Os níveis de água mais profundos atingidos no poço CBA 9, acompanham o comportamento de variação dos níveis mais superficiais e 
estão bem acima do nível dinâmico, devido os baixos valores de vazão e volume explotados.

No poço CBA 12, nota-se claramente uma tendência de rebaixamento constante do nível da água, o qual não recupera até o nível estático e ultrapassa o nível dinâmico. Logo, mesmo que a vazão e o volume de água explotado neste poço estejam abaixo do projetado, o nível de água segue rebaixando.
Este comportamento do nível de água pode estar relacionado ao tempo de bombeamento acima do projetado associado a um período sem bombeamento descontínuo, conforme indicado pelos dados do SIGAS. Outro fator que poderia contribuir para o rebaixamento deste poço é a interferência do bombeamento de outros poços.

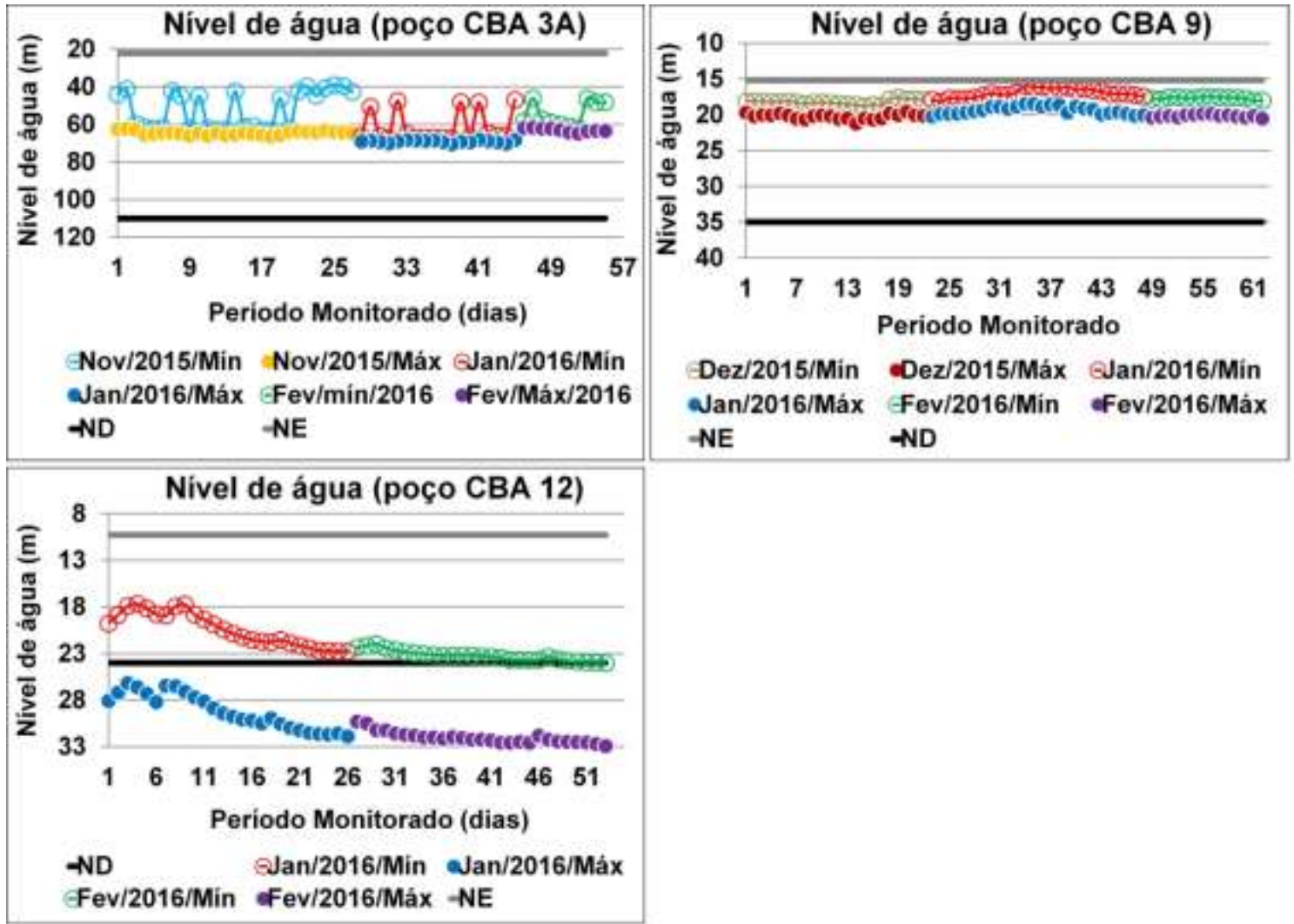

Figura 15 - Valores dos níveis mais superficiais e profundos de água atingidos nos poços analisados Figure 15 - Values of the surface and deep water levels reached in the analyzed wells

O Poço CBA 3 A está operando, na maior parte do período monitorado, com tempo de bombeamento acima do projetado, com intervalos de tempo sem bombeamento descontínuos, mesmo que a vazão bombeada esteja abaixo da projetada os valores de volume de água explotado, na metade do período monitorado, estão acima do valor de projeto, devido ao prolongado período de funcionamento do poço. Todos estes fatores contribuíram para o comportamento de nível de água que pode ser observado na figura 15 , a pouca variação dos níveis de água mais profundos atingidos no poço é em decorrência da estabilidade observada no comportamento da vazão bombeada, os níveis de água mais superficiais, que praticamente coincidiram com os níveis mais profundos, são relativos aos dias em que o tempo de bombeamento foi de $24 \mathrm{~h}$. Assim como no poço CBA 9, a variação dós níveis de água no poço CBA 3A ocorreram dentro do intervalo de variação previsto em projeto e os níveis mais superficiais também não retornaram ao nível estático de projeto. Além disso, os níveis mais superficiais identificados no poço $3 \mathrm{~A}$, que foram atingidos quando do período sem bombeamento, ficaram abaixo da seção filtrante instalada no poço ( 25 a 35 metros). Isso pode evidenciar que em função da 
extração de maiores volumes de água, bem como do pequeno tempo de repouso, ocorreram rebaixamentos dos níveis de água com perda de produção das fraturas localizadas nas entradas de água que são captadas pelas secções filtrantes.

O monitoramento do nível de água nos poços, realizado atualmente pela CORSAN, ocorre raramente, sendo que quando ocorre, o mesmo é realizado durante o dia e não necessariamente nos momentos em que o poço está com ou sem bombeamento. Dessa forma, não há como avaliar se o nível que está sendo medido, corresponde a um nível máximo ou mínimo, que possivelmente ocorrem nos períodos de maior bombeamento e descanso.

\subsection{Diagnóstico da análise individual do monitoramento realizado pelo SIGAS}

O monitoramento realizado pelo SIGAS se demostrou satisfatório e necessário para poços que captam água de aquíferos fraturados e que são utilizados para abastecimento público.

As limitações existentes no monitoramento realizado atualmente pela CORSAN estão associadas ao fato de o mesmo ser realizado de forma manual e depender da visita de um técnico da companhia para realização do mesmo, sendo impossível a realização de um monitoramento mais detalhado.

\section{REFERÊNCIAS}

BORTOLIN, T. A., REGINATO, P. A. R., LEÃO, M. I., \& SCHNEIDER, V. E. Hidrogeologia e hidroquímica dos aquíferos fraturados associados às rochas vulcânicas ácidas no Município de Carlos Barbosa (RS). Ambiente \& Água-An Interdisciplinary Journal of Applied Science, 9(1), 55-67, 2014.

BORTOLIN, TAISON ANDERSON; REGINATO, PEDRO ANTONIO ROEHE ; LEÃO, MARCOS IMÉRIO; SCHNEIDER, VANIA ELISABETE. Relação entre padrões hidroquímicos e as profundidades de fraturas com entradas de água em rochas vulcânicas ácidas da
O benefício de um sistema de monitoramento totalmente automatizado como o SIGAS, para o controle individual dos poços é a possibilidade de detalhar, em intervalos, o tempo com e sem bombeamento operado, permitindo a identificação das influências da demanda na operação do poço.

\section{CONCLUSÃO}

O SIGAS se demostrou capaz de proporcionar um monitoramento com o nível de detalhamento necessário e auxiliar de forma ímpar na gestão da operação dos poços, para tornar as condições de explotação dos mesmos mais coerentes. A partir dos dados coletados pelo SIGAS foi possível identificar a influência da demanda na operação dos poços, as condições de explotação dos mesmos e o reflexo desta explotação contínua nos níveis de água. Com o detalhamento do tempo de bombeamento em intervalos, ficou claro que o tempo sem bombeamento registrado pela CORSAN, é inferior ao que efetivamente $o$ poço possuiu para se recuperar, por ser operado de forma intervalada. Além disso, foi possível verificar que cada poço analisado respondeu de forma diferente as condições de explotação, o que já era esperado devido os poços captarem água de aquíferos fraturados e serem explotado de diferentes formas.

formação serra geral. Rev. Águas Subterrâneas, v. 30, p. 99-118, 2016.

CPRM. (2010) Mapeamento geológico integrado da bacia hidrográfica do Guaíba: carta geológica: FolhaSH.22-V-D - Caxias do Sul. Companhia de Pesquisas de Recursos Minerais. Porto Alegre (Brasil). 1 mapa color. Escala 1:250.000. Material cartográfico.

CPRM. Mapa Hidrogeológico do Estado do Rio Grande do Sul. Porto Alegre, RS, 2005. 1 mapa. Escala 1:750.000. 
DIAS, F.A. Caracterização Estrutural e Hidrogeológica do Sistema Aquífero Serra Geral (SASG) na região de Carlos Barbosa (RS). Trabalho de Conclusão de Curso. Instituto de Geociências, Universidade Federal do Rio Grande do Sul. Porto Alegre, 2013. 58 p.

IBGE - INSTITUTO BRASILEIRO DE GEOGRAFIA E ESTATÍSTICA. Pesquisa Nacional de Saneamento Básico - 2008. Rio de Janeiro, 2010.

MACHADO, J.L.F.; FREITAS, M.A. de. Projeto Mapa Hidrogeológico do Rio Grande do Sul: relatório final. Porto Alegre. CPRM. 65p. il. mapa. 2005.

MOURÃO, M.A.A. Projeto "Implantação de Rede Integrada de Monitoramento das Águas Subterrâneas". 2009. Disponível em:< http://www.cprm.gov.br/publique/media/proposta _monitoramento_CPRM_2009.pdf > Acesso em: 10 de março, 2016.

REGINATO, P. A. R.; BORTOLIN, T. A.; LEAO, M. I.; DIAS, F. A.; DUTRA, T. O.; PAIM, R. A. Avaliação da Circulação da Água Subterrânea em Aquíferos Fraturados com Base na Interpretação das Entradas de Água e Estruturas das Rochas Vulcânicas na Região de Carlos Barbosa (RS). In: Anais do XVIII Congresso
Brasileiro De Águas Subterrâneas. Belo Horizonte - Minas Gerais., 2014.

REGINATO, P. A. R.; LEAO, M. I. ; BORTOLIN, T. A. ; DUTRA, T. O. ; ATHAYDE, G. B. ; ATHAYDE, C. V. M. Circulação da Água Subterrânea nas Rochas Vulcânicas da Formação Serra Geral na Região Nordeste do Estado do Rio Grande do Sul. In: Congresso Brasileiro de Geologia de Engenharia, 15., 2015. Anais... Bento Gonçalves, 2015.

REGINATO, P.A.R.; STRIEDER, A.J. Integração de Dados Geológicos na Prospecção de Aquíferos Fraturados na Formação Serra Geral. Revista da Associação Brasileira de Águas Subterrâneas. v.20, n.1, p. 1-14, 2006.

ROISENBERG, A.; VIERO, A. O Vulcanismo Mesozoico da Bacia do Paraná no Rio Grande do Sul. In: HOLZ, M.; DE ROS, L.F. (Edit.). Geologia do Rio Grande do Sul. Porto Alegre: CIGO/UFRGS. Porto Alegre, 2002. 444p.

VIERO, Ana Cláudia; SILVA, Diogo Rodrigues Andrade da (Orgs.). Geodiversidade do Estado do Rio Grande do Sul. Porto Alegre: CPRM, 2010. 1 DVD. Programa Geologia do Brasil PGB. Levantamento da Geodiversidade. 